\begin{tabular}{|c|c|}
\hline Title & Characteristics of leachate from pyrolysis residue of sewage sludge \\
\hline Author(s) & Hwang, I.H.; Ouchi, Y .; Matsuto, T. \\
\hline Citation & $\begin{array}{l}\text { Chemosphere, 68(10), 1913-1919 } \\
\text { https:/doi.org/10.1016/.chemosphere.2007.02.060 }\end{array}$ \\
\hline Issue Date & 2007-08 \\
\hline Doc URL & http:/hdl.handle.net/2115/33053 \\
\hline Type & article (author version) \\
\hline File Information & matsuto5.pdf \\
\hline
\end{tabular}

Instructions for use 
Chemosphere 68 (2007) 1913-1919

\title{
Characteristics of leachate from pyrolysis residue of sewage sludge
}

\author{
I.H. Hwang*, Y. Ouchi, T. Matsuto \\ Laboratory of Solid Waste Disposal Engineering \\ Graduate School of Engineering \\ Hokkaido University \\ Kita 13, Nishi 8, Kita-ku \\ Sapporo 060-8628, Japan
}

*Corresponding author. Tel./fax: +81-11-706-6830/6831.

E-mail address: ihwang@eng.hokudai.ac.jp (I.H. Hwang). 


\section{Abstract}

The pyrolysis residue (SP) of sewage sludge (SS) produced at $500{ }^{\circ} \mathrm{C}$ was subjected to batch and column leaching tests to investigate the release of its organic and inorganic constituents and metals. For comparison, incineration ash (SI) obtained from a SS incinerator was also tested. Pyrolysis and incineration reduced organic matter of SS from $0.78 \mathrm{~kg} \mathrm{~kg}^{-1}$-dry SS to 0.16 and $0.01 \mathrm{~kg} \mathrm{~kg}^{-1}$-dry SS, respectively. Heavy metals remained in SP without being volatilized, although $\mathrm{Cd}$ and $\mathrm{Pb}$ were transferred into the off-gas during incineration.

In the batch leaching test with the leaching liquid-to-solid mass ratio $(\mathrm{L} / \mathrm{S})=10$, the $\mathrm{pH}$ of the SS, SP, and SI filtrates was 6.3, 7.9, and 11.0, respectively. The total

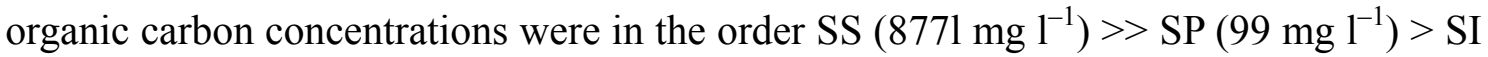
(26 $\mathrm{mg} \mathrm{l}^{-1}$ ). The SP and SI filtrates met the landfill standard for the $\mathrm{Cd}$ and $\mathrm{Pb}$ concentrations $\left(<0.3 \mathrm{mg}^{-1}\right)$. In the column tests, although the SP contained more organic matter than that of SI, its carbon discharge into the leachate under aerobic conditions was similar to that of SI under anaerobic conditions. The leaching of heavy metals, such as $\mathrm{Cd}, \mathrm{Cr}, \mathrm{Pb}$, and $\mathrm{Zn}$, was also suppressed in $\mathrm{SP}$ during the active decomposition of organic matter.

We demonstrated that pyrolysis reduces the potential release of pollutants from sewage sludge in landfill, making it a promising method of treating sewage sludge before landfilling.

Keywords: Batch and column leaching tests; Incineration ash; Landfilling; Pyrolysis residue; Sewage sludge 


\section{Introduction}

The thermal treatment of sewage sludge is considered one of the best treatment methods, since dumping in the sea, direct landfilling, and agricultural utilization have been limited or prohibited. The remarkable volume reduction in sewage sludge through incineration is attractive for countries that have difficulty in securing landfill sites. For example, in Japan, over two million tons of sewage sludge (on a dry basis) were generated in 2002 and about 89\% of that was incinerated (Sannomiya and Kato, 2004).

However, such large-scale thermal conversion of solid to gas requires extensive flue gas cleaning and safe disposal of toxic heavy metals concentrated in final residue. Regulations related to incineration and landfilling stipulate strict criteria for gas emissions and require detailed information on the composition and leachability of the residues (Lopes et al., 2003). Werther and Ogada (1999) suggested that the capital and operating costs of gas purification and ash disposal were driving forces for seeking alternatives to the mono-combustion of sewage sludge. To this end, sewage sludge pyrolysis can be considered an alternative.

Pyrolysis is the thermal degradation of material in the absence of air or in an oxygen-deficient atmosphere. The three major products of pyrolysis are gas, liquid (oil and tar), and carbonaceous residue (char). Many researchers have investigated the product yield and characteristics of sewage sludge pyrolysis (Kaminsky and Kummer, 1989; Rumphorst and Ringel, 1994; Caballero et al., 1997; Inguanzo et al., 2002; Gascó et al., 2005; Shen and Zhang, 2005; Domínguez et al., 2006; Karayildirim et al., 2006). Conesa et al. (1997) established the pyrolysis kinetic model of sewage sludge, in which three different organic fractions decompose independently. 
Compared to incineration, pyrolysis has the following advantages: the amount of flue gas to be cleaned decreases, the generation of acidic gases and dioxins are inhibited under reducing conditions, and the release of heavy metals concentrated in the pyrolysis residue is well suppressed. Kistler et al. (1987) studied the behavior of heavy metals such as $\mathrm{Cr}, \mathrm{Ni}, \mathrm{Cu}, \mathrm{Zn}, \mathrm{Cd}, \mathrm{Pb}$, and $\mathrm{Hg}$ during sewage sludge pyrolysis and found that those metals were highly immobile in the pyrolysis residue due to the well buffered neutral to alkaline properties of the char.

Previously, we characterized chars derived from various solid wastes, including sewage sludge (Hwang et al., 2007). As sewage sludge char produced at $500{ }^{\circ} \mathrm{C}$ had a high ash content and low heating value, it was considered landfill material rather than an alternative fuel. Although several studies have examined metal release from the pyrolysis residue of sewage sludge (Kistler et al., 1987; Kaminsky and Kummer, 1989; Rumphorst and Ringel, 1994; Shinogi et al., 2003), they were limited to batch leaching tests or were performed without considering landfill conditions, such as the redox potential and microbial activity.

Therefore, we measured the release of the organic and inorganic constituents and metals from the pyrolysis residue of sewage sludge in column tests under simulated landfill conditions. Bottom ash obtained from a sewage sludge incinerator was tested together to compare the environmental loads of the leachates depending on thermal treatment. 


\title{
2. Material and methods
}

\author{
2.1. Sample preparation
}

\subsubsection{Sewage sludge and incineration ash}

$10 \mathrm{~kg}$ of dewatered sewage sludge were obtained from a sewage treatment plant with a capacity of $3600 \mathrm{~m}^{3} \mathrm{~d}^{-1}$ sewage in April 2004. This dewatered sewage sludge is referred to as SS. The moisture content of SS was about 75\%. For further experiments, SS was dried at $60^{\circ} \mathrm{C}$ until no weight change was observed.

This plant uses an incinerator to treat $550 \mathrm{t} \mathrm{d}^{-1}$ dewatered sewage sludge. During the drying process before incineration, calcium hydroxide is added to dewatered sewage to control arsenic release into the leachate. The weight ratio of calcium hydroxide to dewatered sewage sludge is 0.2 based on the dry weight. The incineration temperature ranged from 900 to $1000{ }^{\circ} \mathrm{C}$ and the average retention time was $1 \mathrm{~h}$. About $5 \mathrm{~kg}$ of incineration ash were sampled from an ash conveyor line, which is referred to as SI.

\subsubsection{Pyrolysis residue}

250 to $300 \mathrm{~g} \mathrm{~h}^{-1}$ of dry SS was loaded to a laboratory-scale rotary kiln-type reactor $(\phi 0.15 \mathrm{~m} \times 1.2 \mathrm{~m})$ with using a screw feeder and it was pyrolyzed at $500{ }^{\circ} \mathrm{C}$ (Hwang et al., 2007). Nitrogen was used as the carrier gas at a rate of $111 \mathrm{~min}^{-1}$ to maintain an inert atmosphere. The slope angle and rotation rate of the kiln were adjusted to $0.8^{\circ}$ and $2 \mathrm{rpm}$, respectively, to maintain a retention time of $1 \mathrm{~h}$. After pyrolysis and cooling, the solid residue was weighed. The pyrolysis residue obtained from dry SS is subsequently referred to as SP. 


\subsection{Experiments}

\subsubsection{Organic matter and metal content}

SS, SP, and SI were pulverized to homogeneity in a ball mill for $30 \mathrm{~min}$. Ignition loss at $600{ }^{\circ} \mathrm{C}$ is used as a kind of index for organic matter and is also nearly equal to the sum of volatile matter and fixed carbon determined by proximate analysis (JISC, 2004). The organic matter of SS and SP was estimated by proximate analysis whereas that of SI was obtained from ignition loss at $600{ }^{\circ} \mathrm{C}$ for $3 \mathrm{~h}$. The microwave-assisted acid digestion method was used to decompose the solid matrix before measuring the metal content of the samples (USEPA, 1996).

\subsubsection{Batch and column leaching tests}

Japanese leaching test no. 13 (JLT-13; Environment Agency of Japan, 1973) was used to measure the leaching concentrations of organic matter and metals from SS, SP, and SI. A 10 g dry sample was immersed in a flask containing $100 \mathrm{ml}$ of distilled water, and it was capped and shaken horizontally for $6 \mathrm{~h}$ at $200 \mathrm{rpm}$. The mixture was filtered using $1 \mu \mathrm{m}$ pore filter paper, and the filtrate was prepared for measuring $\mathrm{pH}$, total organic carbon (TOC), and metals such as $\mathrm{Cd}, \mathrm{Cr}, \mathrm{Pb}, \mathrm{Zn}, \mathrm{Cu}, \mathrm{Na}, \mathrm{K}$, and $\mathrm{Mg}$.

In addition, three $0.1 \times 0.4 \mathrm{~m}(\mathrm{D} \times \mathrm{H})$ transparent acrylic columns were prepared for the column tests: two were packed with $0.9 \mathrm{~kg}$ of dry SP and one was filled with 1.5 $\mathrm{kg}$ of dry SI. The initial moisture content and effective bed height of the packing material were adjusted to $17 \%$ and $0.24 \mathrm{~m}$, respectively. Two separate SP columns and one SI column were kept under aerobic, anaerobic, and anaerobic conditions, 
respectively. The upper and lower parts of the aerobic column were open to air, while the anaerobic columns were airtight. To facilitate microbial activity under the given conditions, the supernatant obtained from a mixture of soil and distilled water was seeded into the aerobic column, whereas the supernatant from anaerobically digested sludge was added to the anaerobic column. All three columns were placed in a room at $30{ }^{\circ} \mathrm{C}$.

Every two weeks, $200 \mathrm{ml}$ of distilled water were injected into each column for eighteen weeks. For the anaerobic columns, micro-tubing pumps were used to sprinkle distilled water to prevent air permeation. After $24 \mathrm{~h}$, the leachate was collected at the lower part of the column and weighed with an electric balance. The upper and lower parts of the anaerobic column were purged with nitrogen to drive out any air that may have entered the column during the sampling procedure. The $\mathrm{pH}$, electrical conductivity (EC), oxidation-reduction potential (ORP) of the leachate were measured as quickly as possible. Each leachate was filtered using $1 \mu \mathrm{m}$ pore filter paper before measuring the TOC, 5 day biochemical oxygen demand (BOD), total nitrogen $(\mathrm{TN})$, ammonia $\left(\mathrm{NH}_{4}\right)$, inorganic carbon (IC), chloride, and sulfate ion. To measure metal concentrations $(\mathrm{Cd}$, $\mathrm{Cr}, \mathrm{Pb}, \mathrm{Zn}, \mathrm{Cu}, \mathrm{K}, \mathrm{Na}$, and $\mathrm{Mg}$ ), the leachate was filtered through a $0.45 \mu \mathrm{m}$ pore filter paper and acidified with one to two drops of concentrated nitric acid.

\subsubsection{Analytical methods}

The $\mathrm{pH}, \mathrm{EC}$, and ORP were measured using glass electrode methods. A simultaneous TOC-TN analyzer (TOC-V CPH/CPN; Shimadzu) was used to measure the TOC, TN, and IC concentrations. The BOD and $\mathrm{NH}_{4}$ concentrations were measured using the methods of the Japan Society for Analytical Chemistry (JSAC, 1994). The 
concentrations of $\mathrm{Cd}, \mathrm{Cr}$, and $\mathrm{Pb}$ were analyzed using graphite furnace atomic absorption spectrometry (AAS; Z-8200; Hitachi), whereas the concentrations of $\mathrm{Zn}, \mathrm{Cu}$, and $\mathrm{Mg}$ were analyzed using inductively coupled plasma atomic emission spectrometry (ICPS-7500; Shimadzu). Finally, K and Na were measured using flame AAS (Z-8200;

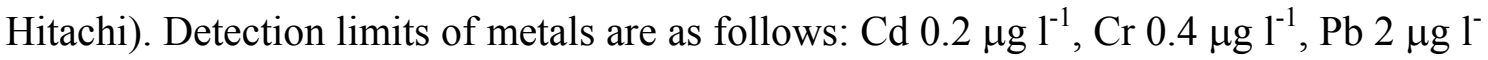
${ }^{1}, \mathrm{Zn} 1 \mu \mathrm{g}{ }^{-1}, \mathrm{Cu} 1 \mu \mathrm{g} \mathrm{l^{-1 }}, \mathrm{K}_{0.1} \mathrm{mg}^{-1}$, Na $0.1 \mathrm{mg} \mathrm{l}^{-1}$, and $\mathrm{Mg} 1 \mu \mathrm{g} \mathrm{l}^{-1}$.

2.3. Estimating the total amounts of released constituents

The total amounts of organic and inorganic constituents and metals released from $1 \mathrm{~kg}$ of dry SS according to pyrolysis and incineration were estimated as follows:

$$
M_{i}=\frac{\sum_{j=1}^{n}\left(C_{i j} \times V_{j}\right)}{\frac{W}{\lambda}},
$$

where $M_{i}$ is the total amount of constituent $i$ released, $C_{i j}$ is the concentration of constitu ent $i$ in the $j$-th sample $\left(\mathrm{mg}^{-1}\right), \quad V_{j}$ is the leachate volume of the $j$ th sample (l), $W$ is the weight of the packed material (kgdry), and $\lambda$ is the ratio of the solid residue to dry SS by weight.

\section{Results and discussion}

3.1. Weight reduction by pyrolysis and incineration 
As illustrated in Fig. 1, the total solids in the SS was reduced to 0.37 and $0.38 \mathrm{~kg}$ $\mathrm{kg}^{-1}$ dry SS by pyrolysis and incineration, respectively $\left(\lambda_{\mathrm{SP}}=0.37\right.$ and $\left.\lambda_{\mathrm{SI}}=0.38\right)$. In addition, the organic matter in the SS $\left(0.78 \mathrm{~kg} \mathrm{~kg}^{-1}\right.$ dry SS) decreased to 0.16 and 0.01 $\mathrm{kg} \mathrm{kg}^{-1}$ dry SS, respectively. Although the organic matter was largely degraded by incineration, $\lambda_{\mathrm{SI}}$ was similar to $\lambda_{\mathrm{SP}}$, owing to the calcium hydroxide added during the drying process before incineration. In general, calcium hydroxide is converted into calcium oxide and water on heating at above $800{ }^{\circ} \mathrm{C}$. Therefore, the weight of calcium oxide in SI was estimated to be $0.15(0.2 \times 56 / 74) \mathrm{kg} \mathrm{kg}^{-1}$ dry SS, as shown in Fig. 1 .

3.2. Metal contents of SS, SP, and SI

Table 1 shows the metal contents of SS, SP, and SI. In order to understand the metal balances among SS, SP, and SI, the metal contents of SS were counted from the metal contents of SP and SI. Most metals in the SS remained in the SP. However, some of the $\mathrm{Cd}, \mathrm{Pb}$, and $\mathrm{Zn}$ in the SI seemed to volatize during incineration. Kistler et al. (1987) reported that $\mathrm{Cr}, \mathrm{Cu}, \mathrm{Zn}$, and $\mathrm{Pb}$ remained in the char during pyrolysis at temperatures up to $705^{\circ} \mathrm{C}$, while the $\mathrm{Cd}$ was reduced to $\mathrm{Cd}^{0}$ and volatilized to the offgas at temperatures above $600{ }^{\circ} \mathrm{C}$. As we conducted the pyrolysis at $500{ }^{\circ} \mathrm{C}$, the $\mathrm{Cd}$ remained in the char without volatilization.

\subsection{Leaching characteristics during JLT-13}

Table 2 shows the $\mathrm{pH}$, TOC, and metal concentrations of SS, SP, and SI filtrates obtained according to JLT-13. The $\mathrm{pH}$ of the SS, SP, and SI filtrates was $6.3,7.9$, and 
11.0, respectively. The high $\mathrm{pH}$ of SI was caused by the large quantity of calcium oxide it contained. The TOC released from SS, SP, and SI shows that pyrolysis and incineration also reduced the soluble organic matter considerably.

Pyrolysis and incineration are thought to suppress heavy metal leaching. The $\mathrm{Cd}$, $\mathrm{Pb}$, and $\mathrm{Zn}$ concentrations in the SI filtrate were below the detection limits. $\mathrm{Cd}, \mathrm{Cr}, \mathrm{Pb}$, and $\mathrm{Zn}$ were essentially immobilized in SP. Thus, the SP and SI filtrates met the landfill standard for the $\mathrm{Cd}$ and $\mathrm{Pb}$ concentrations $\left(<0.3 \mathrm{mg}^{-1}\right)$. The leaching ratios of those metals calculated from the total amount and amount in the leachate were nearly zero, as shown in Table 2 . In contrast, alkali metals tended to be released readily compared to heavy metals. The high acid-buffering $\mathrm{pH}$ of incineration ash and the surface properties of pyrolysis residue might be the reasons for the immobilization of heavy metals (Kistler et al., 1987; Inguanzo et al., 2002; Hwang et al., 2007).

\subsection{Results of the column tests}

\subsubsection{Gas generation}

In the aerobic SP column (SP-A), the gas concentration was checked to determine whether air permeated the column well. Beginning 2 wk after setting up the column, the oxygen concentration averaged $20.4 \pm 0.7 \%$ (mean $\pm \mathrm{SD})$.

Over the course of the experiment, $\mathrm{CO}_{2} 20 \mathrm{mmol} \mathrm{kg}^{-1} \mathrm{SP}$ and $\mathrm{H}_{2} 4 \mathrm{mmol} \mathrm{kg}^{-1} \mathrm{SP}$ were emitted from the anaerobic SP column (SP-An), whereas no gas was generated from the anaerobic SI column (SI-An) because the microbial activity was hindered by the high $\mathrm{pH}$. 


\subsubsection{The $\mathrm{pH}, E C$, and $O R P$}

Figure 2 plots the changes in the $\mathrm{pH}$ and $\mathrm{EC}$ of the leachate versus the cumulative liquid (distilled water) to solid (packed material) weight ratio, i.e. L/S. The $\mathrm{pH}$ did not change significantly throughout the experiment (Fig. 2a). The $\mathrm{pH}$ of the leachates from SP-A, SP-An, and SI-An was in the range of 7.9-8.5, 7.5-8.1, and 11.8-12.2, respectively, and they were nearly the same as the $\mathrm{pH}$ of SP and SI under JLT-13 (Table 2). The slightly lower $\mathrm{pH}$ of the SP-An leachate can be explained by the accumulation of organic acid due to anaerobic microbial reactions. Biodegradable organic matter was promptly decomposed into carbon dioxide under aerobic conditions, whereas it was first decomposed into organic acids under anaerobic conditions.

Except for the initial period of unsaturation with $\mathrm{L} / \mathrm{S}=0-1$, the $\mathrm{EC}$ values of the SP-A, SP-An, and SI-An leachates continued to decrease with L/S, indicating that the concentrations of dissolved constituents were reduced by the normal washout (Fig. 2b).

The ORP values of SP-A, SP-An, and SI-An were in the range of 210-300 and 190-240, and 40-80 mV (Eh), respectively. Even though both SP-An and SI-An were maintained airtight conditions, the ORP did not show negative values. This is because leachate might not represent the true redox potential of the bed due to the reason that ORP was measured $24 \mathrm{~h}$ after the start of water injection under the atmosphere.

\subsubsection{TOC, BOD, $\mathrm{TN}, \mathrm{NH}_{4}-\mathrm{N}, \mathrm{IC}, \mathrm{Cl}^{-}$, and $\mathrm{SO}_{4}{ }^{2-}$}

Figure 3 plots the TOC, $\mathrm{BOD}, \mathrm{TN}, \mathrm{NH}_{4}-\mathrm{N}, \mathrm{IC}, \mathrm{Cl}^{-}$, and $\mathrm{SO}_{4}{ }^{2-}$ concentrations versus the cumulative $\mathrm{L} / \mathrm{S}$ ratio. 
In SP-A (Fig. 3a), the TOC and BOD decreased rapidly from 459 to $51 \mathrm{mg}^{-1}$ and from 445 to $2 \mathrm{mg} \mathrm{l}^{-1}$, respectively, until $\mathrm{L} / \mathrm{S}=1.1$ (8 wk after setting up the column) and then decreased slowly until L/S $=2.2$.

In SP-An (Fig. 3b), the decreases in the TOC and BOD concentrations were slightly slower than in SP-A (Fig. 3a) because the organic acid produced by anaerobic degradation was measured as TOC and BOD. The TOC and BOD concentrations decreased from 568 to $109 \mathrm{mg} \mathrm{l}^{-1}$ and from 643 to $11 \mathrm{mg} \mathrm{l}^{-1}$, respectively, until $\mathrm{L} / \mathrm{S}=$ 1.4. The inorganic carbon concentration increased from 20 to $127 \mathrm{mg}^{-1}$ until $\mathrm{L} / \mathrm{S}=0.4$ and then decreased.

As depicted in Fig. 3c, the TOC and BOD concentrations were similar as was their rate of decrease. Most of the carbon compounds in SI are thought to be biodegradable organic matter. Nevertheless, microbial decomposition was hindered or did not occur because of the high $\mathrm{pH}$. Accordingly, any biodegradable organic matter was simply washed out by distilled water without microbial degradation.

The $\mathrm{TN}$ and $\mathrm{NH}_{4}-\mathrm{N}$ concentrations in SP-A were three to four times lower than in SP-An (Figs. $3 \mathrm{a}$ and $3 \mathrm{~b}$ ). The rapid decreases in the TN and $\mathrm{NH}_{4}$ concentrations in SPA might have resulted from assimilation caused by aerobic microorganisms and by ammonia nitrification. In contrast, the initial $\mathrm{TN}$ and $\mathrm{NH}_{4}-\mathrm{N}$ concentrations in the SI-An leachate were considerably low $\left(<10 \mathrm{mg}^{-1}\right)$ because a large amount of nitrogen had already been lost during the sewage sludge incineration. Similar to the release of TOC and BOD, the $\mathrm{TN}$ and $\mathrm{NH}_{4}$ in SI-An were also simply washed out by distilled water and discharged into the leachate (Fig. 3c).

The decrease in inactive compounds, such as chloride, is an index of the washout rate by normal rainfall. The chloride concentrations in the SP columns decreased from 
224-278 to $128-145 \mathrm{mg} \mathrm{l}^{-1}$ (Figs. 3a and 3b). Similarly, the chloride concentration in SI-An decreased linearly from 361 to $135 \mathrm{mg} \mathrm{l}^{-1}$ (Fig. 3c).

The pattern of sulfate release from the SP columns differed depending on whether the conditions were aerobic or anaerobic. As shown in Fig. 3a, the sulfate concentration was nearly constant under aerobic conditions because it was decreased by normal washing out, whereas it decreased sharply to below $10 \mathrm{mg} \mathrm{l}^{-1}$ until $\mathrm{L} / \mathrm{S}=1.4$ under anaerobic conditions (Fig. 3b). The abrupt drop in the sulfate concentration in the leachate might be explained by the reduction of sulfate besides washing out. In the SIAn, the sulfate concentration decreased in parallel to that of chloride, indicating that it was released via washout (Fig. 3c).

\subsubsection{Heavy metals}

Figure 4 plots the $\mathrm{Cd}, \mathrm{Cr}, \mathrm{Pb}$, and $\mathrm{Zn}$ concentrations in leachate versus the cumulative $\mathrm{L} / \mathrm{S}$ ratio. The $\mathrm{Cd}$ concentration was $2 \mu \mathrm{g} \mathrm{l^{-1 }}$ at maximum and decreased continuously in SP-A, whereas it was not detected in SP-An after $\mathrm{L} / \mathrm{S}=0.4$. This is because CdS is precipitated via the reduction of sulfate. As shown in Fig. 3a, the sulfate concentration in SP-An decreased drastically after L/S $=0.4$ with the reduction of sulfate: $\mathrm{SO}_{4}{ }^{2-} \rightarrow \mathrm{S}^{2-}$. In SI-An, no Cd was detected throughout the experiment.

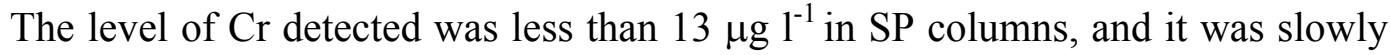
washed out by distilled water. The SI-An leachate contained 80-190 $\mu \mathrm{g} \mathrm{l^{-1 }} \mathrm{Cr}$, which was six to fifteen times higher compared to the SP columns.

The $\mathrm{Pb}$ concentrations were almost below the detection limit $\left(2 \mu \mathrm{g} \mathrm{l^{-1 }}\right)$ in SP-A and SI-An, except for some fluctuations. The Pb in SP-An was slightly higher than in SP-A, but decreased slowly to $<2 \mu \mathrm{g} 1^{-1}$. 
The $\mathrm{Zn}$ concentrations decreased to $100 \mu \mathrm{g} 1^{-1}$ in both SP columns. Based on the similar leaching patterns of SP-A and SP-An (Figs. 4a and 4b), washout by distilled water controlled the $\mathrm{Zn}$ release.

3.5. Total release of carbon, nitrogen, and heavy metals

Table 3 shows the total amounts of carbon, nitrogen, and heavy metals released into the leachate for $18 \mathrm{wk}$ assuming that $1 \mathrm{~kg}$ of dry SS is pyrolyzed or incinerated and then their residues are landfilled under aerobic or anaerobic conditions. The release of carbon and nitrogen into the leachate was reduced considerably by pyrolysis and incineration. The TOC release into the leachates of SP-A, SP-An, and SI-An was 62, 133, and $52 \mathrm{mg} \mathrm{kg}^{-1}$ dry SS, respectively; i.e., the order of carbon release was SP-An > $\mathrm{SP}-\mathrm{A} \approx \mathrm{SI}-\mathrm{An}$. Since the TOC release was in the order SS $\left(87710 \mathrm{mg} \mathrm{kg}^{-1}\right.$ dry SS $)>>$ SP $\left(366 \mathrm{mg} \mathrm{kg}^{-1}\right.$ dry SS) > SI (99 $\mathrm{mg} \mathrm{kg}^{-1}$ dry SS) for JLT-13 (see Table 2), the results of column tests indicate that the biodegradable organic matter in SP actively decomposed into carbon dioxide under aerobic conditions. In SP-An, $88 \mathrm{mg} \mathrm{C} \mathrm{kg}{ }^{-1}$ dry SS was emitted as carbon dioxide into the air (see section 3.4.1). Accordingly, about $34 \%$ of released carbon $\left(\mathrm{TOC}+\mathrm{IC}+\right.$ carbon as $\mathrm{CO}_{2}$ ) was emitted to the air and $66 \%$ was discharged into the leachate. In contrast, in SI-An, all $58 \mathrm{mg} \mathrm{C} \mathrm{kg}^{-1}$ dry SS was released to the leachate. Since the SP-A column was open to ambient air, the gas was not measured quantitatively.

The TN release was in the order SP-An $\left(47 \mathrm{mg} \mathrm{kg}^{-1}\right.$ dry SS $)>$ SP-A $\left(17 \mathrm{mg} \mathrm{kg}^{-1}\right.$ dry SS) > SI-An (3 $\mathrm{mg} \mathrm{kg}^{-1}$ dry SS). This was because the nitrogen content of SI was markedly smaller than that of SP. 
While the release of $\mathrm{Cd}, \mathrm{Pb}$, and $\mathrm{Zn}$ was in the order $\mathrm{SP}-\mathrm{A} \geq \mathrm{SP}-\mathrm{An}>\mathrm{SI}-\mathrm{An}, \mathrm{Cr}$ was SI-An $>$ SP-A $=$ SP-An. The amount of heavy metals released from SP was larger than that from SI except $\mathrm{Cr}$; however, as shown in Table 3, the difference in the total leaching of heavy metals depending on the pretreatment methods and landfill conditions was very minute.

\section{Conclusions}

We investigated the pyrolysis residue and incineration ash obtained from sewage sludge as pretreated materials for landfilling based on the concentrations of organic and inorganic constituents and heavy metals released in batch and column leaching tests.

Although the SP contained relatively more organic matter than the SI and held most metals without volatilization during thermal treatment, the releasing of organic matter and heavy metals was considerably reduced in its batch leaching test.

Moreover, in the column leaching tests, the release of organic matter from the SP into the leachate was decreased to the same level of SI, since it was biodegraded under the neutral to weak alkali conditions. In contrast, the decomposition of organic matter in SI was inhibited by the high $\mathrm{pH}$.

The amount of heavy metals released from the SP was greater than from incineration ash; however, the amount leached was very small in terms of ppb. In addition, we found little difference in the amount leached between aerobic and anaerobic conditions. SP showed good ability to retain heavy metals without the addition of extra chemicals such as calcium hydroxide for SI. 
The potential release of organic and inorganic constituents and metals from sewage sludge can be reduced by pyrolysis, which could serve as a suitable thermal treatment method for sewage sludge prior to landfilling.

\section{References}

Caballero, J.A., Front, R., Marcilla, A., Conesa, J.A., 1997. Characterization of sewage sludges by primary and secondary pyrolysis. J. Anal. Appl. Pyrol. 40/41, 433-450.

Conesa, J.A., Marcilla, A., Prats, D., Rodriguez-Pastor, M., 1997. Kinetic study of the pyrolysis of sewage sludge. Waste Manage. Res. 15, 293-305.

Domínguez, A., Menéndez, J.A., Inguanzo, M., Pís, J.J., 2006. Production of bio-fuels by high temperature pyrolysis of sewage sludge using conventional and microwave heating. Bioresource Technol. 97, 1185-1193.

Environment Agency of Japan, 1973. Environment Agency Notification No. 13 for Measuring Method for Metals in Industrial Wastes, Japan.

Gascó, G., Blanco, C.G., Guerrero, F., Méndez Lázaro, A.M., 2005. The influence of organic matter on sewage sludge pyrolysis. J. Anal. Appl. Pyrol. 74, 413-420.

Hwang, I.H., Matsuto, T., Tanaka, N., Sasaki, Y., Tanaami, K., 2007. Characterization of char derived from various types of solid wastes from the standpoint of fuel recovery and pretreatment before landfilling. Waste Manage., doi:10.1016/j.wasman. 2006.11.007.

Inguanzo, M., Domínguez, A., Menéndez, J.A., Blanco, C.G., Pis, J.J., 2002. On the pyrolysis of sewage sludge: the influence of pyrolysis conditions on solid, liquid and 
gas fractions. J. Anal. Appl. Pyrol. 63, 209-222.

JSAC, 1994. Water Analysis, $4^{\text {th }}$ Edition. Japan Society for Analytical Chemistry, Hokkaido Branch, Japan.

JISC, 2004. JIS M 8812: Coal and Coke-Methods for Proximate Analysis, Japanese Industrial Standards Committee, Tokyo.

Kaminsky, W., Kummer, A.B., 1989. Fluidized bed pyrolysis of digested sewage sludge. J. Anal. Appl. Pyrol. 16, 27-35.

Karayildirim, T., Yanik, J., Yuksel, M., Bockhorn, H., 2006. Characterisation of products from pyrolysis of waste sludges. Fuel 85, 1498-1508.

Kistler, R.C., Widmer, F., Brunner, P.H., 1987. Behavior of chromium, nickel, copper, zinc, cadmium, mercury, and lead during the pyrolysis of sewage sludge. Environ. Sci. Technol. 21, 704-708.

Lopes, M.H., Abelha, P., Lapa, N., Oliveira, J.S., Cabrita, I., Gulyurtlu, I., 2003. The behaviour of ashes and heavy metals during the co-combustion of sewage sludges in a fluidised bed. Waste Manage. 23, 859-870.

Rumphorst, M.P., Ringel, H.D., 1994. Pyrolysis of sewage sludge and use of pyrolysis coke. J. Anal. Appl. Pyrol. 28, 137-155.

Sannomiya, T., Kato, H., 2004. State and task on sewage sludge utilization. Saisei to Riyou 103, 13-25.

Shen, L., Zhang, D.-K., 2005. Low-temperature pyrolysis of sewage sludge and putrescible garbage for fuel oil production. Fuel 84, 809-815.

Shinogi, Y., Yoshida, H., Koizumi, T., Yamaoka, M., Saito, T., 2003. Basic characteristics of low-temperature carbon products from waste sludge. Adv. Environ. Res. 7, 661-665. 
USEPA, 1996. Test Methods for Evaluating Solid Waste, Physical/Chemical Methods SW-846 Method 3052: Microwave Assisted Acid Digestion of Siliceous and Organically Based Matrices. Office of Solid Waste's Manual of EPA-Approved Analytical Methods, Washington, DC.

Werther, J., Ogada, T., 1999. Sewage sludge combustion. Prog. Energ. Combust. 25, $55-116$. 
Table 1

Metal balance of SS estimated from the metal content of SP and SI

SS SP

SI

\begin{tabular}{lcccc}
\hline Measured & Estimated & Estimated & \\
& from SP $^{\text {a }}$ & from SI $^{b}$ & Measured & Measured
\end{tabular}

\begin{tabular}{lrrrrr}
\hline $\mathrm{Cd}$ & 2.0 & 2.0 & $<0.04$ & 5.5 & $<0.1$ \\
$\mathrm{Cr}$ & 25.2 & 26.2 & 22.5 & 70.7 & 59.2 \\
$\mathrm{~Pb}$ & 34.8 & 36.1 & 13.0 & 97.6 & 34.1 \\
$\mathrm{Zn}$ & 569 & 589 & 413 & 1593 & 1088 \\
$\mathrm{Cu}$ & 25.1 & 26.0 & 92.0 & 70.2 & 242 \\
$\mathrm{~K}$ & 1227 & 1271 & 1117 & 3434 & 2939 \\
$\mathrm{Na}$ & 764 & 792 & 1125 & 2140 & 2960 \\
$\mathrm{Mg}$ & 1955 & 2025 & 2296 & 5473 & 6042 \\
\hline $\begin{array}{l}\text { Units: mg kg } \\
\text { a }:=(\text { Metal content of SP) } \times 0.37 \\
\mathrm{b}:=(\text { Metal content of SI) } \times 0.38\end{array}$ & & & & \\
\end{tabular}


Table 2

The $\mathrm{pH}, \mathrm{TOC}$, and metal leaching concentration and leaching ratio

\begin{tabular}{|c|c|c|c|}
\hline & $\mathrm{SS}^{\mathrm{a}}$ & SP & SI \\
\hline $\mathrm{pH}(-)$ & 6.3 & 7.9 & 11.0 \\
\hline TOC & 8771 & 99 & 26 \\
\hline $\mathrm{Cd}$ & $0.0056(2.9)$ & $0.0002(0.04)$ & $<0.0002(-)$ \\
\hline $\mathrm{Cr}$ & $0.068(2.7)$ & $0.0025(0.04)$ & $0.022(0.4)$ \\
\hline $\mathrm{Pb}$ & $0.056(1.6)$ & $0.003(0.03)$ & $<0.002(-)$ \\
\hline $\mathrm{Zn}$ & $3.4(6.0)$ & $0.017(0.01)$ & $<0.001(-)$ \\
\hline $\mathrm{Cu}$ & $1.57(62.6)$ & $0.0086(0.1)$ & $0.0094(0.04)$ \\
\hline $\mathrm{K}$ & 76 (61.9) & $36(10.5)$ & $68(23.1)$ \\
\hline $\mathrm{Na}$ & $42(55.0)$ & $19(8.9)$ & $37(12.5)$ \\
\hline $\mathrm{Mg}$ & $47(24.0)$ & $9.8(1.8)$ & $0.18(0.03)$ \\
\hline \multicolumn{4}{|c|}{$\begin{array}{l}\text { a: dry SS } \\
\text { Units: } \mathrm{mg} \mathrm{l}^{-1} \\
(\quad): \text { metal leaching ratio }(\%)=\left[\text { leaching concentration by JLT-10, } \mathrm{mg}^{-1}\right] \div[\text { metal content in Table } 1 \\
\left.\mathrm{mg} \mathrm{kg}^{-1}\right] \times 10(\mathrm{~L} / \mathrm{S}) \times 100 \\
-: \text { not estimated }\end{array}$} \\
\hline
\end{tabular}


Table 3

Amounts of constituents released from $1 \mathrm{~kg}$ of SS according to the pretreatment methods and aerobic or anaerobic conditions

\begin{tabular}{|c|c|c|c|c|}
\hline & $\mathrm{SS}^{\mathrm{a}}$ & SP-Aerobic & SP-Anaerobic & SI-Anaerobic \\
\hline Total weight of material (kg-dry) & 0.01 & 0.9 & 0.9 & 1.5 \\
\hline Total inflow of distilled water (1) & 0.1 & 2.0 & 2.0 & 2.0 \\
\hline Cumulative $\mathrm{L} / \mathrm{S}$ ratio & 10 & 2.2 & 2.2 & 1.3 \\
\hline TOC & $8.8 \times 10^{4}$ & 62 & 133 & 52 \\
\hline $\mathrm{IC}$ & 42 & 14 & 40 & 6 \\
\hline BOD & $8.8 \times 10^{4}$ & 33 & 96 & 100 \\
\hline $\mathrm{TN}$ & $2.1 \times 10^{4}$ & 17 & 47 & 3 \\
\hline $\mathrm{NH}_{4}-\mathrm{N}$ & $6.6 \times 10^{3}$ & 8 & 30 & 1 \\
\hline $\mathrm{Cd}$ & $5.6 \times 10^{-2}$ & $5 \times 10^{-4}$ & $2 \times 10^{-4}$ & - \\
\hline $\mathrm{Cr}$ & $6.8 \times 10^{-1}$ & $3 \times 10^{-3}$ & $3 \times 10^{-3}$ & $4.5 \times 10^{-2}$ \\
\hline $\mathrm{Pb}$ & $5.6 \times 10^{-1}$ & $5 \times 10^{-3}$ & $2 \times 10^{-3}$ & $8 \times 10^{-4}$ \\
\hline Zn & 34 & $1.4 \times 10^{-1}$ & $1.5 \times 10^{-1}$ & $4 \times 10^{-3}$ \\
\hline $\mathrm{Cu}$ & 16 & $4.0 \times 10^{-2}$ & $2.5 \times 10^{-2}$ & $8 \times 10^{-3}$ \\
\hline K & 759 & 30 & 64 & 187 \\
\hline $\mathrm{Na}$ & 417 & 25 & 34 & 75 \\
\hline $\mathrm{Mg}$ & 472 & 16 & 19 & 8 \\
\hline
\end{tabular}

Units: $\mathrm{mg} \mathrm{kg}^{-1}$ dry SS

${ }^{\mathrm{a}}$ : Calculated from JLT-13 (Table 2) 


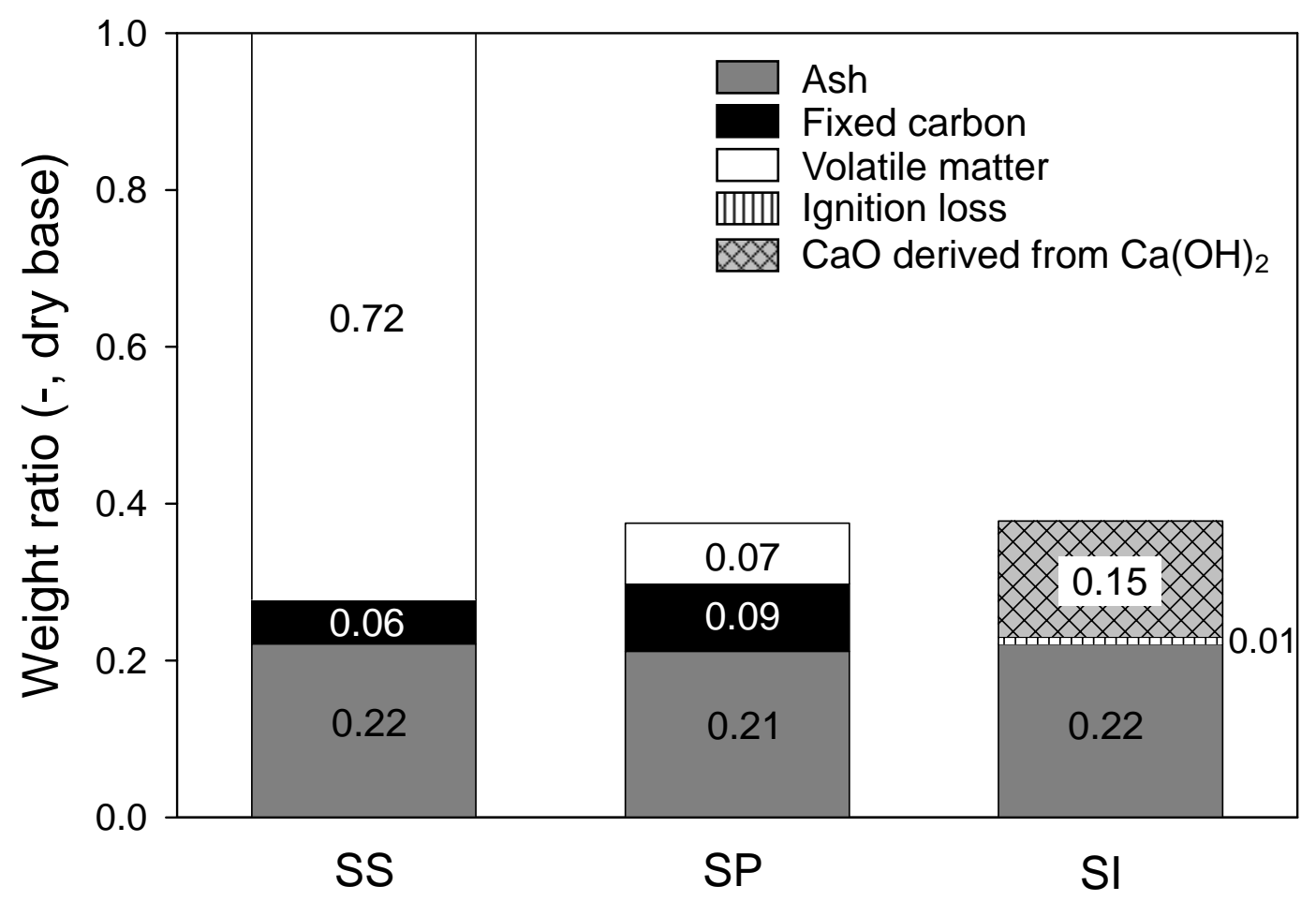

Fig. 1. Weight reductions of SS by pyrolysis and incineration and the composition of SS , SP, and SI. 
(a) $\mathrm{pH}$

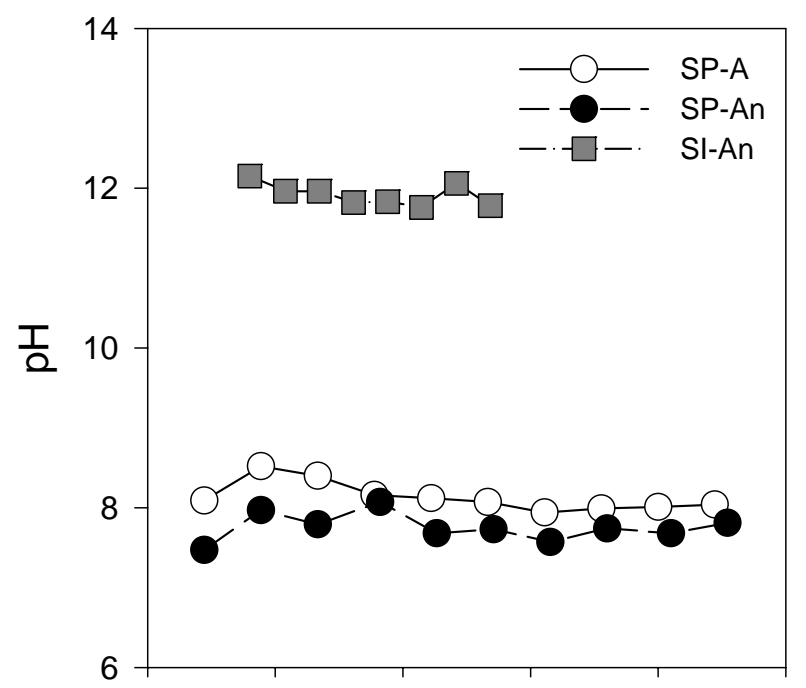

(b) $\mathrm{EC}$

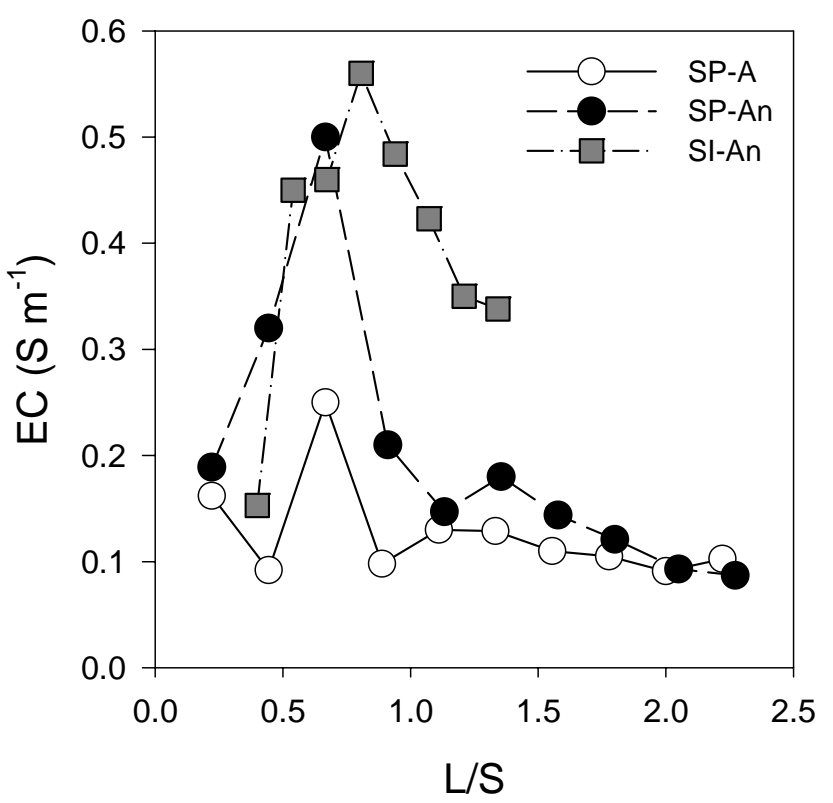

Fig. 2. Changes in $\mathrm{pH}$ and $\mathrm{EC}$ values plotted against the cumulative $\mathrm{L} / \mathrm{S}$ ratio. 
(a) SP-A

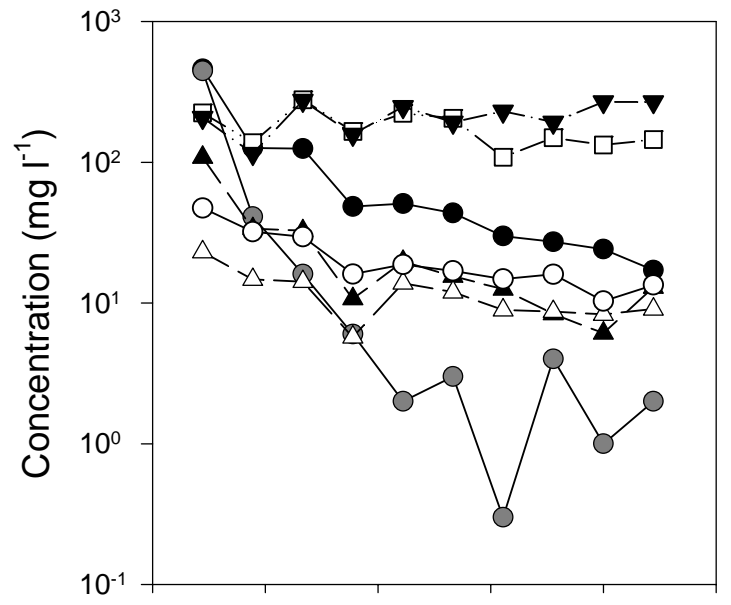

(b) SP-An

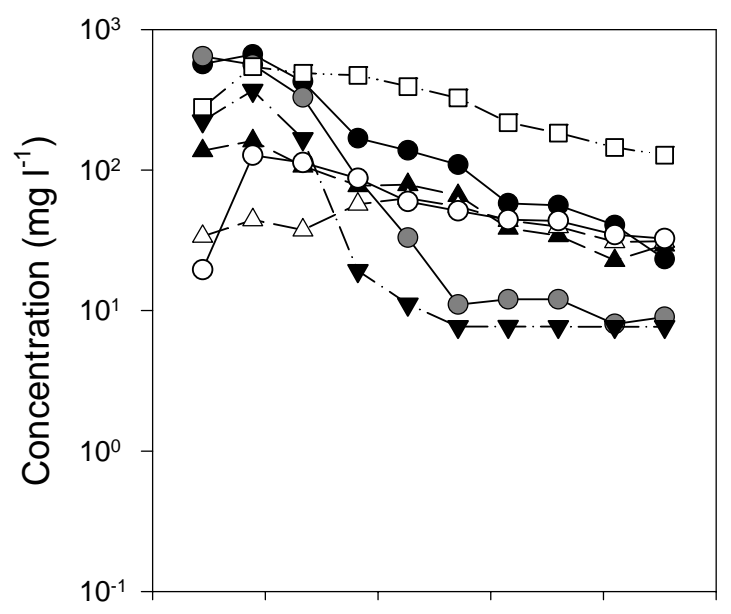

(c) SI-An

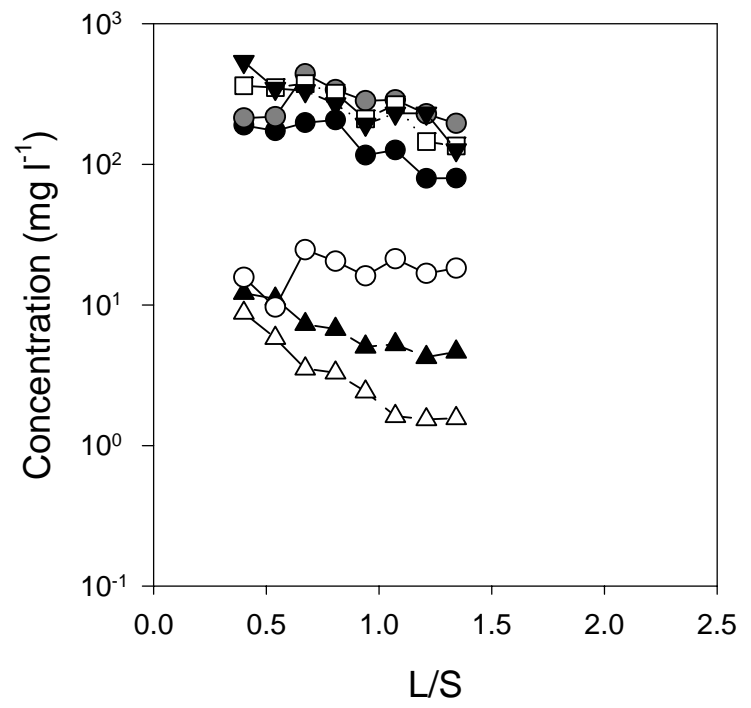

$$
\begin{array}{llll}
\longrightarrow \mathrm{TOC} & -\mathrm{O}-\mathrm{IC} & -\mathrm{BOD} & --\boldsymbol{A}-\mathrm{TN} \\
-\triangle-\mathrm{NH}_{4} \mathrm{~N} & -\square-\mathrm{Cl}^{-} & -\nabla-\mathrm{SO}_{4}{ }^{2-} &
\end{array}
$$

Fig. 3. Changes in the TOC, IC, BOD, TN, $\mathrm{NH}_{4}-\mathrm{N}, \mathrm{Cl}^{-}$, and $\mathrm{SO}_{4}{ }^{2-}$ concentrations of the leachate plotted against the cumulative $\mathrm{L} / \mathrm{S}$ ratio. 
(a) SP-A

(b) SP-An
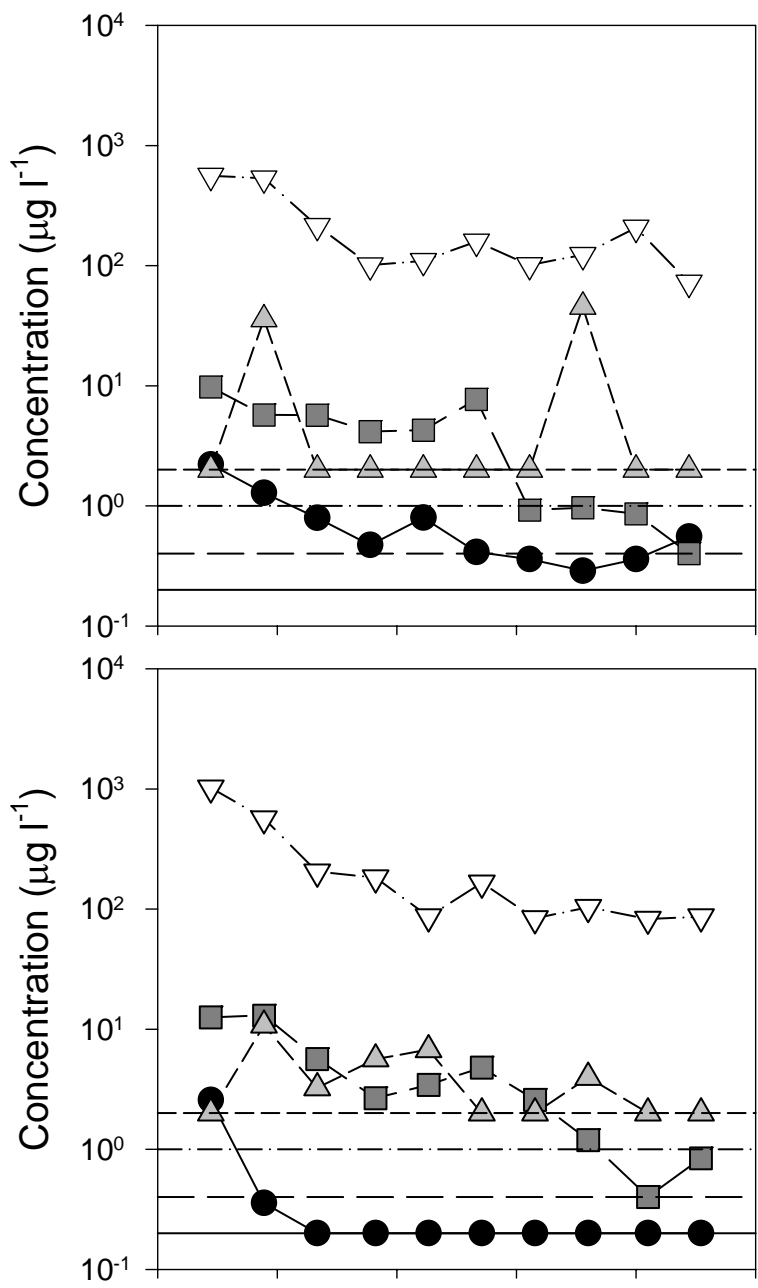

(c) SI-An

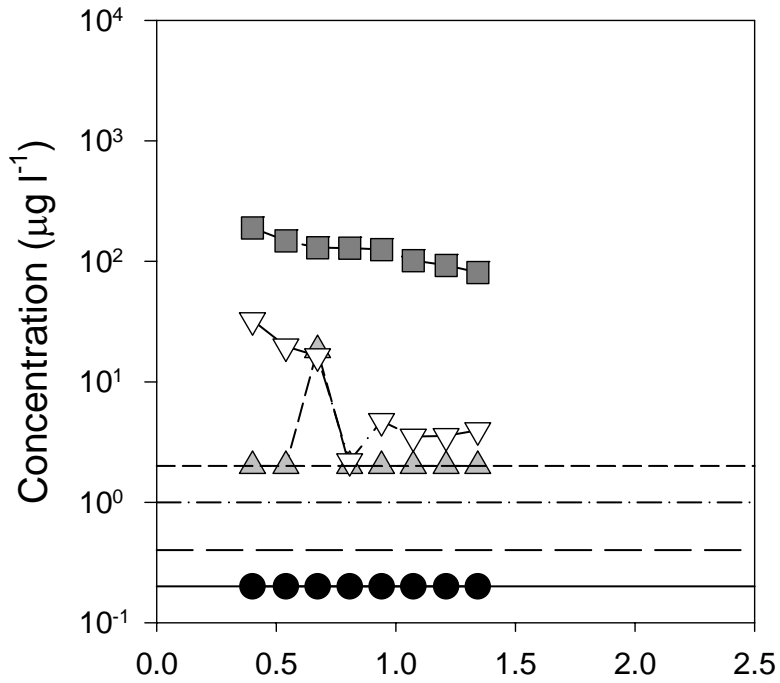

L/S

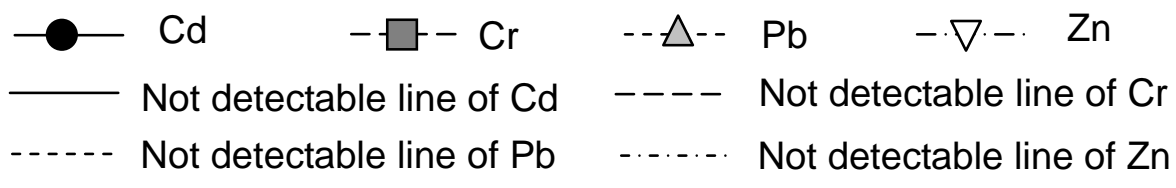

Fig. 4. Changes in the $\mathrm{Cd}, \mathrm{Cr}, \mathrm{Pb}$, and $\mathrm{Zn}$ concentrations of the leachate plotted against the cumulative $\mathrm{L} / \mathrm{S}$ ratio. 